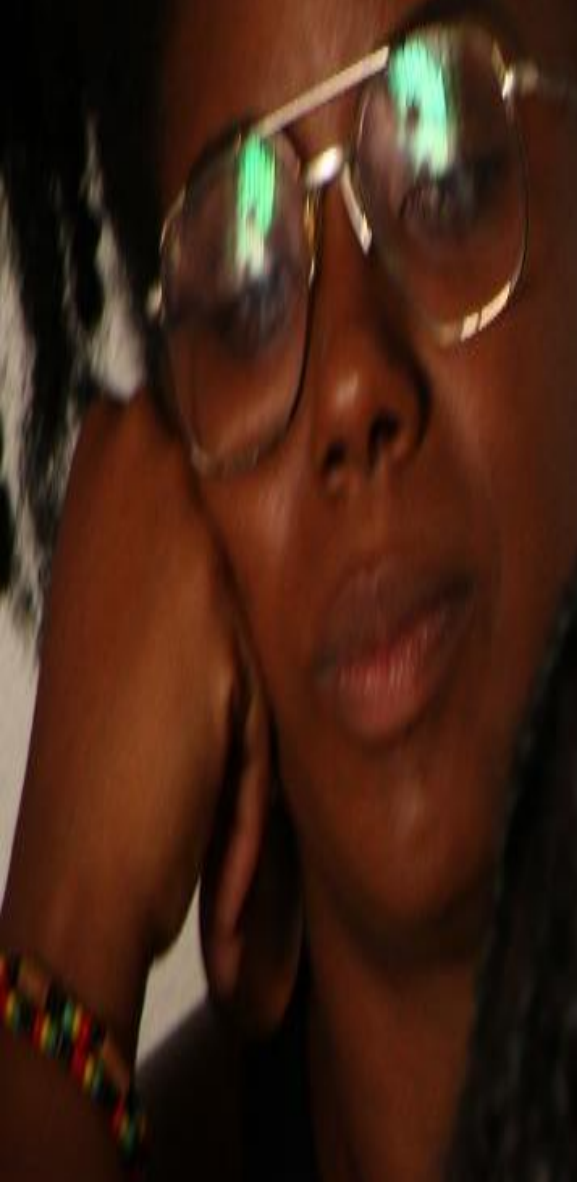




\section{Trens Turísticos em São Paulo: reflexões teóricas sobre o papel da Associação Brasileira de Preservação} Ferroviária (ABPF)

Ewerton Henrique Moraes ${ }^{1}$

Eduardo Romero Oliveira ${ }^{2}$

\footnotetext{
${ }^{1}$ Professor Substituto da Universidade Estadual Paulista Júlio de Mesquita Filho. Mestre em Arquitetura e Urbanismo e Bacharel em Turismo. Mestre em Arquitetura e Urbanismo pela Universidade Estadual Paulista - UNESP na linha Teoria, História e Projeto. Bacharel em Turismo pela mesma universidade. Desde a graduação (iniciação científica) desenvolve pesquisas sobre patrimônio e preservação de bens ferroviários. Possui experiências internacionais, em destaque o estágio de pesquisa realizado na Escuela Técnica Superior de Arquitectura (ETSA) da Universidad de Sevilla (US), Espanha. Atualmente, é professor substituto do curso de Turismo da Universidade Estadual Paulista (UNESP). Email: ewertonhenrique adm@yahoo.com.br
}

2 Professor Assistente Doutor da Universidade Estadual Paulista Júlio de Mesquita Filho. Doutorado em Filosofia pela Universidade de São Paulo. Email: eduardo@rosana.unesp.br 


\section{Resumo}

Atualmente, o Estado de São Paulo conta com seis trens turísticos ativos. Entre estes, a Associação Brasileira de Preservação Ferroviária (ABPF) é responsável pela operação de quatro serviços. Além da operação ferroviária, o grupo tem sido mencionado em ações relacionadas à preservação e implantação de novos projetos. Desta forma, o objetivo é compreender o papel da Associação na preservação e usos atuais do patrimônio ferroviário, especificamente, na operação de trens turísticos em São Paulo. Para isso, utilizamos fontes bibliográficas e documentais, em especial, as publicações da ABPF na Revista Ferrovia. Entre os resultados, destacamos a aproximação entre a proposta original da $A B P F$ e os trens turísticos atuais, além da elaboração do mapa dos trens turísticos em São Paulo.

Palavras chave: Patrimônio, Trens Turísticos, Transporte, Turismo; ABPF.

\section{Abstract}

The Associação Brasileira de Preservação Ferroviária (ABPF) was founded in 1977 and, currently, is responsible for most of the touristic trains in São Paulo. Our objective is to study the actions of the Association in the preservation and current uses of railway heritage, specifically, in the operation of trains in São Paulo. For this, we mainly use bibliographic and documentary sources. Among the results, we emphasized the elaboration of the tourist trains map in São Paulo and the approximation between $A B P F$ and the actual touristic train concepts, associate with heritage preservation.

Keywords: Heritage, Tourist Trains, Transports, Tourism; ABPF.

\section{INTRODUÇÃO}

Em 2015, o Serviço Brasileiro de Apoio às Micro e Pequenas Empresas (SEBRAE) e a Associação Brasileira das Operadoras de Trens Turísticos e Culturais (ABOTTC) publicaram em parceria o Guia Trens Turísticos e Culturais do Brasil (SEBRAE; ABOTTC, 2016) onde são apresentados 20 serviços no país. Entre estes, a Associação Brasileira de Preservação Ferroviária (ABPF) opera nove trens, ou seja, é responsável por quase a metade dos serviços.

Em São Paulo, a situação não é diferente, a Associação é maioria entre os filiados da ABOTTC. Mesmo quando inserimos os serviços não ligados ao grupo de operadores ou não mencionados no livro (SEBRAE; ABOTTC, 2016), casos da Estrada de Ferro Campos do Jordão (EFCJ), Expresso Turístico e outros menores. Atualmente, estão em operação seis trens turísticos, onde quatro são operados pela ABPF (ANTT, 2015). Também têm sido frequentes as menções à Associação em projetos para novos trens turísticos no Estado.

Desta forma, propomos uma reflexão teórica sobre o papel da ABPF na preservação e usos atuais do patrimônio ferroviário, questão abordada a partir dos trens turísticos paulistas. A contribuição da pesquisa para o turismo está em sua abrangência, uma vez que aborda os trens turísticos também através dos aspectos da preservação do patrimônio. Ao longo do texto, demonstraremos aproximações entre os objetivos iniciais da ABPF - indissociáveis do contexto de mudanças no transporte ferroviário - e os trens turísticos atuais, em muito relacionados a um caráter memorialista. 
CENÁRIO, Brasília, V.5, n.9 | $26-40$ | Dez. 2017 | p. 26

Este artigo é parte das reflexões da dissertação Os Bens Ferroviários nos Tombamentos do Estado de São Paulo (1969 - 1984) (MORAES, 2016). O Estudo sobre a ABPF estava integrado aos objetivos de identificação do solicitante do tombamento da Estrada de Ferro Perus Pirapora (EFPP), sendo as considerações sobre o Turismo um avanço decorrente das discussões. A pesquisa foi desenvolvida de maneira exploratória e contou, principalmente, com fontes documentais.

Para compreender os objetivos e propósitos iniciais da ABPF, recorremos a um conjunto de textos com autoria de seus associados. Analisamos as publicações na Revista Ferrovia entre 1979 e 1982, período com publicações contínuas. De maneira complementar, na mesma etapa realizamos entrevistas com Del Bianco (2015) e Moraes (2015), membros da ABPF em sua primeira década de atuação.

Para composição deste artigo, em específico, buscamos identificar os trens turísticos atuais e a presença da ABPF neste setor. Para isso consultamos principalmente publicações da Agência Nacional de Transportes Terrestres (ANTT) e a ABOTTC. Para verificar a existência de novos projetos e a existência de menções ao grupo foi necessário recorrer à periódicos online, selecionamos publicações posteriores a 2011.

Para melhorar a apresentação dos serviços atuais e a atuação da ABPF recorremos aos Sistemas de Informação Geográfica (SIG). Na ocasião identificamos a localização dos trens turísticos de São Paulo (SEBRAE; ABOTTC; 2016; ANTT, 2015) e elaboramos uma nova camada de informação. O produto final foi realizado com o auxílio do software ArcGIS e ferramenta Google Maps (Google).

\section{TRENS TURÍSTICOS: SOBRE A BIBLIOGRAFIA NACIONAL}

Os termos utilizados para mencionar os populares trens turísticos variaram na bibliografia ao longo dos anos. Atualmente, o mais comum é trens turísticos e culturais. O mesmo aparece em publicações do setor público (ANTT, 2015; IPHAN, 2014) e privado (SEBRAE; ABOTTC, 2016).

Na Resolução n`359 da ANTT (2003), legislação promulgada em 2003 e ainda vigente, fala-se em transporte ferroviário com finalidade turística, histórico e cultural. Isso nos sugere que o termo atual abarque mais de um tipo de serviço. A existência de tipos fica clara na leitura dos trens filiados à $A B O T T C$, indicando uma divisão entre trem turístico e trem histórico e cultural. Por exemplo, na apresentação do Trem dos Ingleses (São Paulo/SP) que o define: "trem de caráter Histórico e Cultural, não sendo considerado um Trem Turístico" (ABOTTC, 2017). A separação pode estar vinculada à finalidade e extensão do passeio, contudo, não localizamos uma explicação objetiva. Neste texto, interpretaremos os três termos como sinônimos de trens turísticos.

Na prática, existe uma divisão que requer nossa atenção: trens turísticos e comemorativos. Trata-se de um aspecto legal sobre a operação destes serviços, definido pela Resolução n 359 de 2003 da ANTT (2003). Enquanto os trens comemorativos são caracterizados como um evento 
CENÁRIO, Brasília, V.5, n.9 | $27-40$ | Dez. 2017 | p. 27 específico e isolado, os serviços de finalidade histórica e cultural estão juntos e mesmo não sendo um serviço regular, são abordados com a ideia de continuidade.

A mesma legislação aponta também a forte ou condicionante relação deste tipo de transporte turístico com a preservação do patrimônio:

Art. 11. O transporte ferroviário de passageiros, não regular e eventual, com finalidade histórico-cultural, poderá se caracterizar pela implantação de museu estático e dinâmico, com o fim de contribuir para a preservação do patrimônio histórico e memória das ferrovias (ANTT, 2003).

Na Cartilha de Orientação para projetos deste tipo do Ministério do Turismo esta finalidade aparece com um pouco menos ênfase, sendo o objetivo dos trens turísticos: "[...] agregar valor aos destinos turísticos, contribuindo para a preservação da memória ferroviária, configurando-se em atrativos culturais e produtos turísticos das cidades [...]" (IPHAN, 2014, p. 15).

Na bibliografia, o conceito de ferrovias turísticas proposto por Allis (ALLIS; BRAMBATI, 2010; ALLIS, 2006) é o que mais se aproxima desta relação patrimônio e turismo. Sem divergir das definições básicas propostas por outros autores (PALHARES, 2006; THOMSON, 2004; RONÁ, 2002), Allis (2006) justifica a utilização não pela questão semântica, mas por compreender as particularidades deste tipo de serviço e "[...] ao chamarmos ferrovia turística, damos destaque também ao entorno e as condições paisagísticas intervenientes em sua construção integral" (ALLIS, 2006, p. 123). Nesta lógica, o que a diferencia dos transportes comuns são também a forma de comercialização e os serviços agregados, como poderia ser o acompanhamento de um guia.

Apesar de sua relevância, a definição anterior é limitada quando consideramos os serviços que operam em linhas ativas e não exclusivamente turísticas, casos, por exemplo, do Expresso Turístico da CPTM ou Trem de Guararema, ambos em São Paulo. Não por menos, Lohmann, Fraga e Castro (2013) afirmam que a definição de trem turístico é controversa. Para os autores, a experiência proporcionada pelo deslocamento é um ponto chave para compreender a questão.

Para Thompson (2004) os trens turísticos podem ser divididos em duas categorias: os de tipo 1 tem a paisagem como apelo principal, no segundo caso (tipo 2), o trem é a própria atração por suas características físicas, sendo geralmente equipamento antigo, sobretudo, locomotivas a vapor. Tais considerações foram incorporadas por outros autores enquanto trens cênicos e nostálgicos (LOHMANN; FRAGA; CASTRO, 2013; ALLIS; BRAMBATTI, 2010; ALLIS, 2006; PALHARES, 2006).

Entre os autores citados no último parágrafo é comum também a menção ao contexto das ferrovias no Brasil, situação interpretada sempre como decadente. Dentro do contexto das concessões ferroviárias, a suspensão e atual escassez dos trens de longo percurso retirou o trem do cotidiano dos viajantes, passando assim para o campo nostálgico (FRAGA; CASTRO, 2012; ALLIS; BRAMBATTI, 2010). Também por isso não é incomum ver o trem da Estrada de Ferro Vitória Minas (EFVM) mencionado como trem turístico. Para compreender o exemplo é necessário lembrar as 
diferenças entre o deslocamento integrado aos serviços turísticos e o transporte turístico. No segundo, o meio de transporte é o próprio atrativo e a base para a experiência turística, sendo os cruzeiros marítimos um exemplo claro (PALHARES, 2006; RONÁ, 2002).

Fraga e Castro (2012) afirmam que o trem pode também ser indiretamente o desencadeador da experiência turística, uma vez que existe pouca oferta. Para eles, essa escassez de trens para passageiros pode ser percebida como um acionador da experiência no uso de trens regulares. Infelizmente, essas grandes possibilidades para o turismo geram visões distorcidas em projetos públicos, a percepção do trem enquanto atrativo por excelência. Também por isso, a Cartilha do MTUR (IPHAN, 2014) é clara ao mencionar que um trem turístico e cultural não é suficiente para transformar determinada localidade em um destino turístico, é necessário que o local possua outros atrativos.

Conforme já mencionado, a Cartilha (IPHAN, 2014) apresenta forte relação dos serviços com o patrimônio. Contudo, a revisão bibliográfica deixou claro que nem sempre o uso turístico da ferrovia esteve relacionado ao patrimônio. ${ }^{3}$ Essa aproximação aparece na legislação - Resolução n ${ }^{\circ}$ 359/2003 da ANTT - e de forma gradativa nas publicações a partir dos anos 2000. O processo de privatização da RFFSA é mencionado com frequência e os autores (PAOLILLO; REJOWSKI, 2006; RONÁ, 2002) partilham de uma interpretação de degradação do setor ferroviário. Apesar de receber menções frequentes, essa noção associada ao fim da era ferroviária já é questionada por autores de outras áreas (NUNES, 2009). De toda forma, a escassez dos serviços ferroviários para passageiros influencia o interesse e a experiência dos turistas, ponto onde sim concordamos com o conjunto de autores.

\section{RESULTADOS}

\subsection{Trens Turísticos em São Paulo}

Na página da Agência Nacional de Transportes Terrestres (ANTT) (2015) é possível identificar a autorização para sete trens turísticos e histórico-culturais no Estado de São Paulo. Entre os ausentes está a Estrada de Ferro Campos do Jordão (EFCJ) (2017), ferrovia administrada pela Secretaria Estadual de Transportes Metropolitanos (STM) e que por suas características operacionais transporte regular de passageiros - não demanda autorização similar. Durante a pesquisa identificamos também o Projeto Ferrovia para Todos (PREFEITURA DE BAURU, 2015) e a Estrada de Ferro Perus Pirapora (EFPP) (IFPPC, 2017) com a oferta de passeios ferroviários, contudo, não obtivemos informações sobre as condições legais de operação. Desta forma, chegamos a um total de 10 trens turísticos (vide tabela 1 ).

\footnotetext{
${ }^{3}$ Vide também Quadro 2.7. Artigos sobre transporte publicados em periódicos brasileiros de turismo (LOHMANN; FRAGA; CASTRO, 2013).
} 
CENÁRIO, Brasília, V.5, n.9 | 29 - 40 | Dez. 2017 | p. 29

Tabela 1 - Trens Turísticos em São Paulo

\begin{tabular}{|c|c|c|c|c|c|c|c|}
\hline Nome Comercial & Legenda & Situacao & Responsável pela Operação & Tipo Operador & Tração & Ferrovia Ativa & ABOTTC \\
\hline Estrada de Ferro Campos do Jordão & 1 & Ativo & EFCJ & Poder Público & Diversas & Sim & $?$ \\
\hline Estrada de Ferro Perus Pirapora & 2 & Paralisado & IFPPC & Associação & Vapor & Não & Não \\
\hline Expresso Turístico & 3 & Ativo & CPTM & Poder Público & Diesel & Sim & Não \\
\hline Viação Férrea Campinas Jaguariúna & 4 & Ativo & ABPF & Associação & Vapor & Não & Sim \\
\hline Projeto Ferrovia para Todos & 5 & Paralisado & Prefeitura de Bauru & Poder Público & Vapor & Sim & Não \\
\hline Trem Caipira & 6 & Paralisado & Prefeitura de S.J. Rio Preto & Poder Público & Diesel & Sim & Sim \\
\hline Trem Cultural dos Imigrantes & 7 & Ativo & ABPF & Associação & Vapor & Não & Sim \\
\hline Trem dos Ingleses & 8 & Ativo & ABPF & Associação & Vapor & Não & Sim \\
\hline Trem Moita Bonita & 9 & Paralisado & Prefeitura de Paraguaçu Paulista & Poder Público & Vapor & Sim & Sim \\
\hline Trem de Guararema & 10 & Ativo & ABPF & Associação & Vapor & Sim & $?$ \\
\hline
\end{tabular}

Fonte: Elaborado pelos autores com base em ABPF (2015) e ANTT (2015).

A tração a vapor e a utilização de trechos desativados são predominantes nos serviços turísticos. Entre os trens que circulam em vias ativas, apenas o Trem de Guararema opera com locomotiva a vapor. Neste caso, para que fosse possível atender as normas de segurança, a Locomotiva 353 recebeu alguns equipamentos específicos. 0 trem atende às normas especificas da ANTT e é acompanhado pela concessionária MRS Logística (MRS LOGÍSTICA, 2015).

Figura 1. Mapa Trens Turísticos em São Paulo

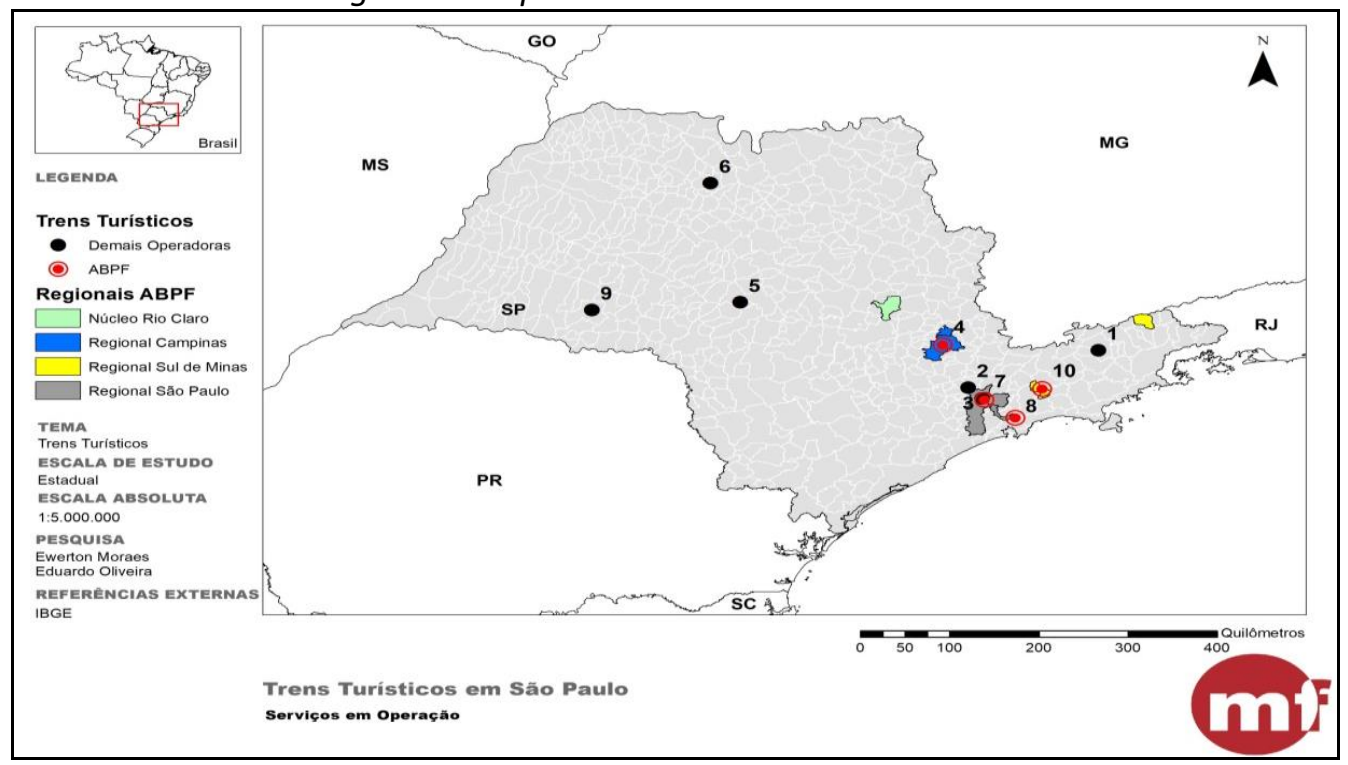

Fonte: Elaborado pelos Autores

A elaboração de mapas nos permitiu identificar também que os trens turísticos estão concentrados principalmente na Região Metropolitana de São Paulo (RMSP) e Vale do Paraíba (vide mapa 1). Obviamente, a oferta destes serviços nas proximidades de grandes aglomerações é um aspecto positivo, contudo, até o momento, não identificamos qualquer relação entre este ou outros fatos relevantes. Por outro lado, a ferramenta nos foi útil para compreender melhor a atuação da ABPF e suas divisões administrativas. São Paulo conta com ações de três regionais e um núcleo da Associação: Regional Sul de Minas; Regional São Paulo; Regional Campinas; e, Núcleo Rio Claro (vide mapa 2). 


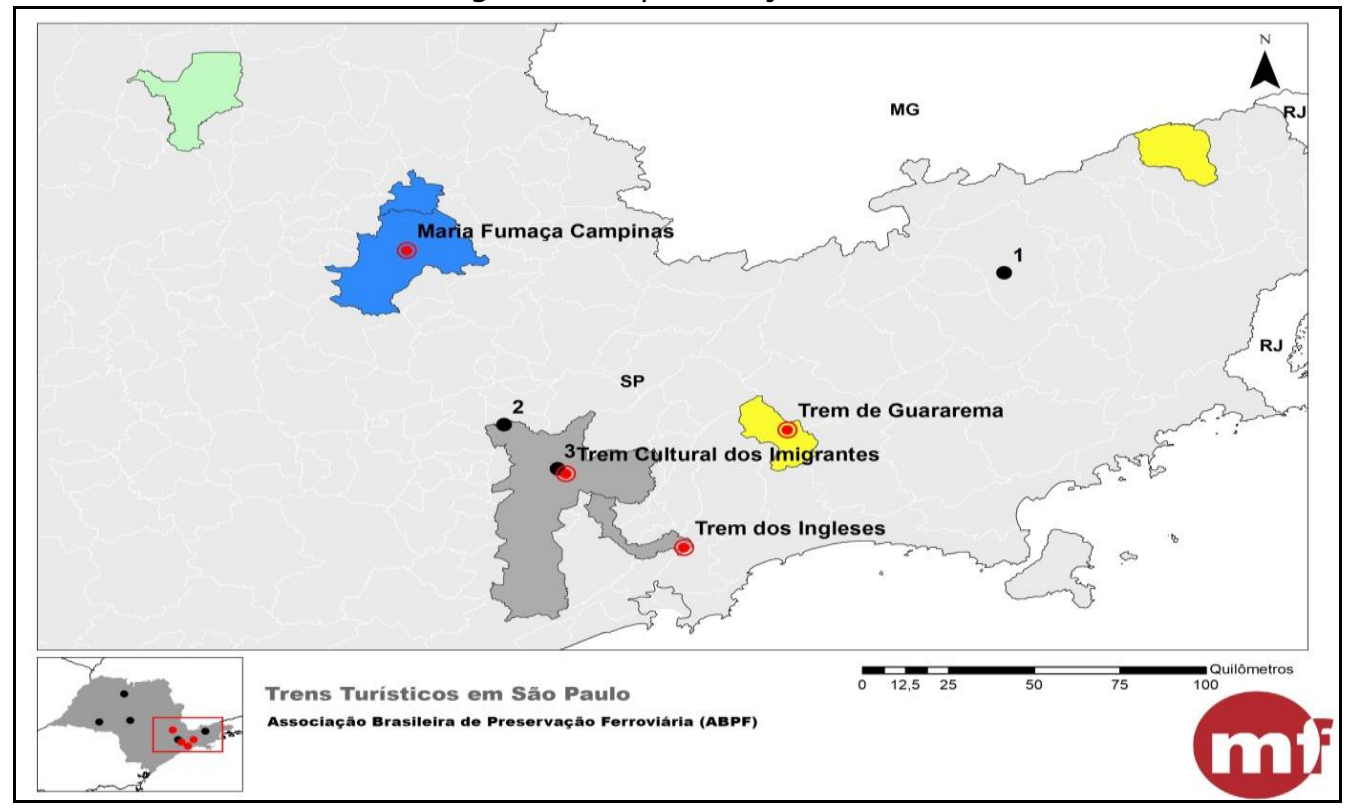

Fonte: Elaborado pelos Autores

Em São Paulo, a ABPF é responsável pela operação de quatro trens turísticos e históricoculturais, além da participação em outros projetos. No Expresso Turístico, por exemplo, a Associação foi responsável por ceder os carros de aço inox que atendem o serviço (CPTM, 2010).

\subsection{A Associação Brasileira de Preservação Ferroviária}

Na bibliografia, a ABPF é apontada como pioneira na operação de trens turísticos e primeira associação voltada à preservação ferroviária (COOPER, 2011; ALLIS; BRAMBATTI, 2010; MATOS, 2010; RIBEIRO, 2007; ALLIS, 2006). É possível afirmar que o grupo tem relações com o surgimento de outras associações com interesses similares, como nos apresenta Matos (2010) e o caso do Rio de Janeiro.

Para Cooper (2011) a cidade de Campinas foi o coração do movimento voluntário de preservação ferroviária no Brasil. O autor faz uma referência ao trecho ferroviário operado pela ABPF e seu modelo de organização enquanto associação. De fato, ainda o interesse pela preservação de objetos ferroviários possivelmente não fosse uma novidade, ${ }^{4}$ a organização da sociedade civil e o trabalho voluntário podem ser considerados diferenciados.

A ABPF é uma Organização da Sociedade Civil de Interesse Público (OSCIP) e, atualmente, está presente em 18 cidades distribuídas em seis Estados: Minas Gerais; Paraná; Rio de Janeiro; Rio Grande do Sul; São Paulo; e, Santa Catarina (ABPF, 2015). Sem fins lucrativos, suas atividades -

\footnotetext{
${ }^{4}$ Essa afirmação contraria os relatos apresentados pelos associados em diferentes entrevistas (DEL BIANCO, 2015; RODRIGUES, 2015; MORAES, 2015) e publicações (ABPF, 2015; RIBEIRO, 2007). Contudo, em 1970, o Instituto Mairiporã demonstrou o interesse em implantar uma ferrovia e um museu ferroviário (REVISTA FERROVIA, 1972). Anterior a esse, em um recorte anexo ao processo da estação ferroviária de Bananal, datada de 1970, a reportagem menciona: "já se pensa, também, em solicitar à Rede Ferroviária Federal — proprietária da estação - a doação de uma velha locomotiva a vapor e alguns metros de trilhos para transformá-la em museu turístico" (PROCESSO CONDEPHAAT15645/69, 1969, p.15).
} 
CENÁRIO, Brasília, V.5, n.9 | $31-40$ | Dez. 2017 | p. 31 inclusive a operação das composições ferroviárias - são feitas por voluntários associados (ABPF, 2015; COOPER, 2011). Conforme consta em sua página, a missão do grupo é "promover o resgate e a conservação do patrimônio histórico ferroviário brasileiro, disponibilizando os bens à visitação pública, desde que a conservação do bem não seja colocada em risco" (ABPF, 2015).

Fundada em 1977, a Associação teve desde o principio uma atuação mais abrangente do que a operação de trens turísticos. Foi justamente uma destas ações, o pedido de tombamento da Estrada de Ferro Perus Pirapora (EFPP), que despertou nosso interesse pela questão. Ao longo de sua trajetória, a ABPF participou também de outros pedidos e campanhas de proteção, destaque para o trecho entre São João Del Rei e Tiradentes da Estrada de Ferro Oeste de Minas junto ao Ministério dos Transportes (ABPF, 2015). Patrimônio reconhecido pelo Instituto do Patrimônio Histórico e Artístico Nacional (IPHAN), o conjunto ferroviário é também um importante trem turístico no cenário nacional, atualmente, operado pela empresa privada VLI.

Além de atender visitantes e pesquisadores, o grupo possui parcerias com a Administração Pública para consultorias e restauração de materiais ferroviários (ABPF, 2015). Na mesma fonte encontramos menções a Prefeitura de Monte Alegre do Sul/SP (restauro de locomotiva a vapor) e Prefeitura de São Carlos (estudo de viabilidade técnica). Possivelmente, a atuação neste setor em São Paulo seja ainda maior, já que a ABPF é mencionada com frequência em noticias sobre novos projetos (tabela 2)

Tabela 2 - Projetos para Trens Turísticos

\begin{tabular}{|c|c|c|c|c|c|c|}
\hline Nome Proposto & Trecho & Responsável & Tamanho & Tração & ABPF & Ano Info. \\
\hline Trem Republicano & Itu - Salto & Consórcio Intermunicipal & - & Vapor & Não & 2017 \\
\hline Sem nome & Itanhém - Peruíbe & Consórcio Intermunicipal & - & Vapor & Sim & 2017 \\
\hline Sem nome & P. Prudente - P. Epitácio & Prefeitura de P. Epitácio & - & Vapor & Não & 2016 \\
\hline Sem nome & A. Prata (SP) - P. Caldas (MG) & Prefeitura Poços de Caldas (MG) & $9 \mathrm{Km}$ & Vapor & Projeto & 2015 \\
\hline Sem nome & Cruzeiro & ABPF - Regional Sul de Minas & - & Vapor & Responsável & 2015 \\
\hline Trem Cultural São Carlos & São Carlos & Prefeitura de São Carlos (SP) & $11 \mathrm{~km}$ & Vapor & Projeto & 2011 \\
\hline Trem Turístico da Sorocabana & Laranjal Paulista e outras & Consórcio Intermunicipal & - & - & Não & 2010 \\
\hline Sem nome & Bauru - Agudos & - & $23 \mathrm{~km}$ & Vapor & Não & 2010 \\
\hline Trem da Cana & Sertãozinho & Prefeitura de Sertãozinho & $10 \mathrm{Km}$ & - & Não & 2010 \\
\hline
\end{tabular}

Fonte: Elaborado pelos autores.

Assim sendo, consideramos que a ABPF é, atualmente, uma referência - não necessariamente positiva - na operação de trens turísticos e culturais. A presença de representantes do grupo na Diretoria Executiva e Conselho Deliberativo da ABOTTC, associação que representa os operadores, reforça nosso argumento. A ABPF ocupa dois entre os quatro cargos da diretoria, além de uma vaga no mencionado conselho.

\subsubsection{A preservação de Locomotivas a Vapor}

Em Fevereiro de 1977, Patrick Dollinger publicou no Jornal Estado de São Paulo o convite para criação de uma associação voltada à preservação de locomotivas a vapor e assuntos ferroviários em 
geral (ABPF, 2015). Ele é considerado fundador e pessoa fundamental para a atuação da ABPF, informação presente tanto na bibliografia (COOPER, 2011; MATOS, 2010; RIBEIRO, 2007) quanto em relatos (MORAES, 2015; DEL BIANCO, 2015; RODRIGUES, 2015). A criação da ABPF ocorreu em setembro do mesmo ano (ABPF, 2015). A efetiva fundação da ABPF ocorreu em setembro de 1977 (ABPF, 2015).

Entre 1979 e 1982, a ABPF publicou de maneira contínua 18 textos na Revista Ferrovia, uma publicação especializada e voltada a temas de interesse de engenheiros ferroviários. ${ }^{5}$ Publicados pouco tempo após a fundação e antes mesmo do inicio da operação da Viação Férrea Campinas Jaguariúna (VFCJ), primeiro trem turístico da $A B P F$, tais documentos foram nossa fonte principal para compreender os objetivos originais da Associação.

A primeira publicação do grupo (DEL BIANCO, 1979) apresenta informações sobre o proposito e a relevância do trabalho, ao final, afirma querer contar com o apoio de todos. Os demais artigos se alternam entre reflexões sobre a preservação da memória ferroviária, ações da ABPF e históricos de ferrovias ou material rodante (tabela 3).

Tabela 3 - Publicações da ABPF (Revista Ferrovia)

\begin{tabular}{lcccc}
\hline Ano & \multicolumn{2}{c}{ Edição N } & Título & Autor \\
\hline 1979 & 69 & NOV/DEZ & Aos Amigos Ferroviários & Alberto H. Del Bianco \\
1979 & 70 & JAN/FEV & Não publicado & - \\
1980 & 71 & MAR/ABR & Sem Título & Patrick Dollinger \\
1980 & 72 & MAI/JUN & Por que Preservar o Patrimônio Histórico Ferroviário & Julio E. C. D. de Moraes \\
1980 & 73 & JUL/AGO & Para que serve um ramal? & Patrick Dollinger \\
1980 & 74 & SET/OUT & Sesquicentenário da Liverpool and Manchester & Sérgio Martire \\
1980 & 75 & NOV/DEZ & Como Preservar o Patrimônio Histórico Ferroviário & Julio E. C. D. de Moraes \\
1981 & 76 & JAN/FEV & Porque Preservar a Locomotiva Elétrica No 6405? & Sérgio Martire \\
1981 & 77 & MAR/ABR & ALCO RSC 1 de 1.000 - Uma Locomotiva ... & Alberto H. Del Bianco \\
1981 & 78 & MAI/JUN & As "Lambretas" da Santos Jundiaí & Sérgio Martire \\
1981 & 79 & JUL/AGO & ALCO FA1 - Uma Locomotiva de Raça & Cid J. Beraldo e Fabio Dantas \\
1981 & 80 & SET/OUT & Companhia de Estradas de Ferro Oeste de Minas & Sérgio Martire \\
1981 & 81 & NOV/DEZ & A Velha Senhora na Trilha da Aventura & Sérgio Martire \\
1981 & 82 & JAN/FEV & Não publicado & - \\
1982 & 83 & MAR/ABR & As Locomotivas "English Eletric" da EFSJ & Alberto H. Del Bianco \\
1982 & 84 & MAI/JUN & O Material Rodante da Viação Férrea Campinas - Jaguariúna & Alberto H. Del Bianco \\
1982 & 85 & JUL/AGO & Não publicado & - \\
1982 & 86 & SET/OUT & Não publicado & - \\
1982 & 87 & NOV/DEZ & O Alargamento da Bitola da E.F. Araraquara & Paulo Modé
\end{tabular}

Fonte: Elaborado pelos autores.

A proposta de operar um trem turístico estava em destaque. Sempre associada aos interesses de preservação o interesse era tratado como museu dinâmico, termo ainda presente nos materiais da ABPF (2015). Ainda na primeira Del Bianco (1979, p. 22) menciona o objetivo de obter um trecho

\footnotetext{
${ }^{5}$ Fundada em 1935, a Revista Ferrovia é um órgão de comunicação oficial da Associação dos Engenheiros da Estrada de Ferro Santos a Jundiaí (AEEFSJ). Com sede em São Paulo, o periódico circula em todas as companhias ferroviárias do Brasil, algumas na América Latina e entidades afins (REVISTA FERROVIA, 1982).
} 
ferroviário desativado "[...] para armazenar o acervo da Associação, e onde, futuramente circulará um trem turístico". As relações com a preservação são ainda mais claras em Dollinger (1980, p.34) quando menciona as finalidades da ABPF:

a) agrupar as pessoas que gostam de ferrovias e tem o espírito de preservação; b) Preservar o material ferroviário de valor histórico - principalmente locomotivas a vapor; c) Guardar o acervo da ABPF em local seguro e restaurá-lo ao seu estado original, em oficina própria com a colaboração de associados; d) Exibir ao público o acervo, dentro do possível em funcionamento através de nosso Museu Dinâmico de Jaguariúna; e) Promover pesquisas culturais e históricas de nosso passado ferroviário.

A mesma publicação evidencia o apoio da RFFSA e Ferrovia Paulista S.A. (FEPASA) em parte das ações, a exemplo da cessão da linha entre Campinas e Jaguariúna $(24,5 \mathrm{~km})$ e permissão de uso de locomotivas a vapor (DOLLINGER, 1980). Por outro lado, isso não exclui as constantes disputas e divergências entre a ABPF e as empresas públicas. É o caso, por exemplo, do pedido de tombamento da E.F. Perus Pirapora e os conflitos com o Governo Federal através da Coordenadoria das Empresas Incorporadas ao Patrimônio Nacional (CEIPN), esta contrária à proteção (AUTOR, 2016). O processo contou com diversas denúncias e manifestações da ABPF, mencionadas aqui como outro exemplo da atuação do grupo.

Considerando a análise conjunta das publicações e ações da ABPF, em especial sua atuação no citado tombamento da EFPP, entendemos que a luta em favor da memória ferroviária se confunde com as ações contra o sucateamento das ferrovias, onde podemos citar, por exemplo, o uso da palavra "destruição" ao tratar da memória (DEL BIANCO, 1979). Desta forma, a mobilização para preservação da memória tem inicio nas atuações contra o sucateamento e ou outras ações consequentes deste processo que coloquem em risco a integridade do acervo.

Assim, com base nas diferentes fontes consultadas, podemos afirmar que a essência dos objetivos originais esteva concentrada no material rodante, em especial, nas locomotivas a vapor.

\subsection{Locomotivas a Vapor em Operação (1966 - 1984)}

Considerando a preservação de locomotivas a vapor como objetivo principal da ABPF no inicio de sua atuação, buscamos levantar informações quantitativas sobre a operação deste tipo de máquinas à época. Para isso, consultamos especificamente o Anuário Estatístico do Brasil (AEB). Quanto ao recorte temporal proposto, representa a chegada de Patrick Dollinger ao Brasil conforme Moraes (2015) e a inauguração da Viação Férrea Campinas Jaguariúna (ABPF, 2015).

No gráfico (figura 3), podemos notar que, de fato, houve uma redução no número de locomotivas a vapor em operação neste período. Conforme o IBGE (BRASIL, 1967), em 1966, o Brasil contava com 815 locomotivas com tração a vapor. EM 1977, esse número era de apenas 24 
equipamentos (BRASIL, 1985). Dessa forma, temos uma redução de aproximadamente $97 \%$ no número de locomotivas.

Operação

Figura 3. Locomotivas a Vapor em

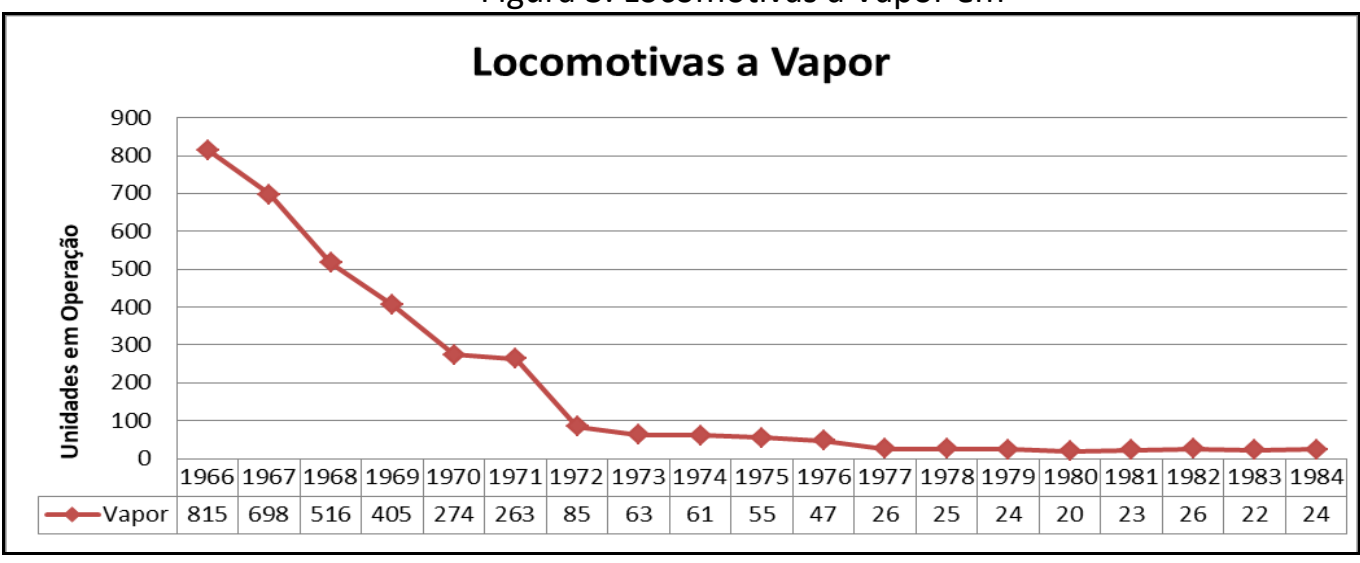

Fonte: Elaborado pelo autor, com base em Brasil (1969; 1971; 1973; 1975; 1978; 1981; 1985)

Figura 4. Locomotivas em Operação por Força Motriz.

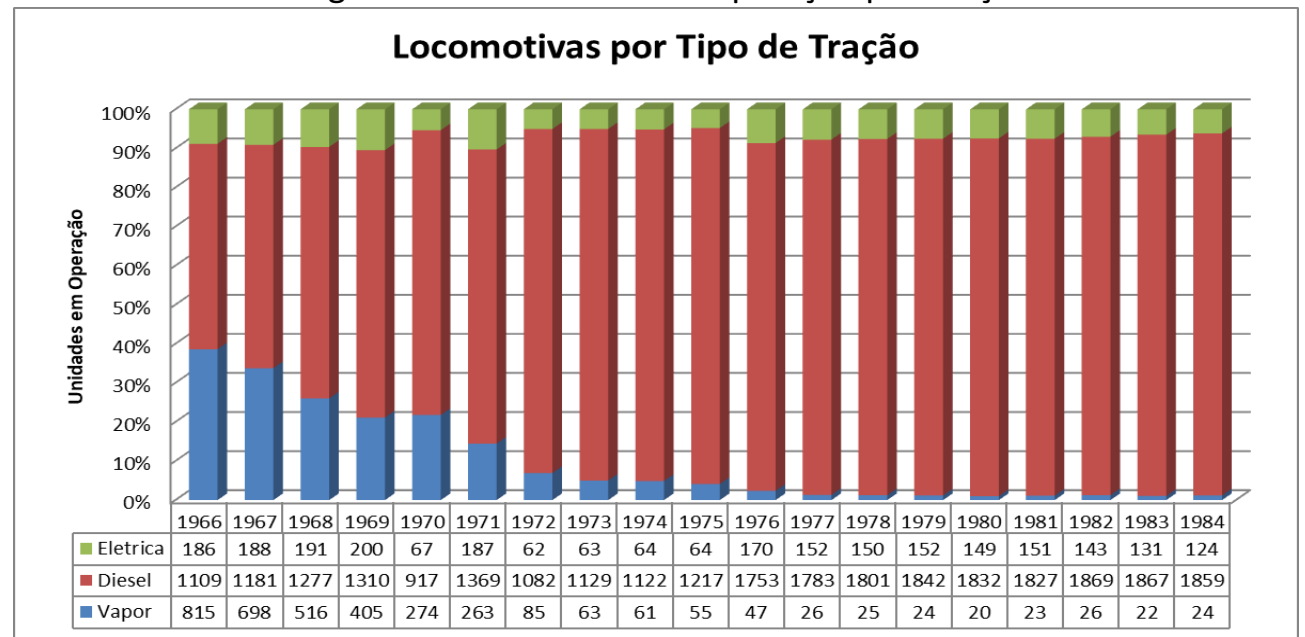

Fonte: Elaborado pelo autor, com base em Brasil (1969; 1971; 1973; 1975; 1978; 1981; 1985)

O número de unidades apresenta estabilidade entre 1977 e 1984, extremo de nosso recorte. Contudo, a tração a vapor apresenta porcentagens praticamente nulas, principalmente, quando comparadas as locomotivas diesel (figura 4). É válido mencionar que as décadas destacadas estão dentro de um contexto de alteração nas políticas de transportes, conforme detalhado no tópico a seguir.

\section{O PAPEL DA ABPF}

\subsection{Sucateamento das Locomotivas?}

A criação da ABPF é indissociável do contexto de alteração das políticas de transportes ocorridas na década de 1970. O período foi marcado pela erradicação de ramais considerados 
"antieconômicos" (ANDREAZA, 1974). Tais mudanças, especificamente a desativação de linhas e substituição de materiais rodantes, foram interpretadas pelo grupo como abandono da história ferroviária (DEL BIANCO, 2015; RODRIGUES, 2015; MORAES, 2015; RIBEIRO, 2007). O mesmo entendimento aparece hoje na página "Associação" como motivação principal para a criação do grupo:

Patrick chegou ao Brasil em 1966 (período de transição da tração a vapor para a diesel) e, preocupado com o abandono da história ferroviária brasileira, resolveu criar uma entidade de preservação nos moldes das existentes na Europa e Estados Unidos (ABPF, 2015).

Por outro lado, a redução de locomotivas a vapor representava também um avanço tecnológico no setor ferroviário, ação exaltada pelo Governo Federal. Em 1972, por exemplo, o então Ministro Mário Andreazza (1974) falou sobre os investimentos e reaparelhamento das ferrovias:

A dieselização completa de nossas estradas de ferro, que, por motivos técnicos e econômicos, se constitui num dos maiores anseios dos administradores ferroviários com a erradicação da tradicional locomotiva a vapor, de inestimáveis serviços prestados no passado, é finalmente uma realidade. (ANDREAZZA, 1974, p.226).6

Dessa forma, identificamos a existência de posições opostas sobre à substituição das locomotivas a vapor: para o Governo, o reaparelhamento e modernização do setor; para a ABPF, o abandono. Em uma leitura atual, podemos apontar a existência de uma tensão entre o valor de uso e valor simbólico (BALLART, 1997); desativar ou substituir equipamentos resultava em um entendimento de descaso com a história.

Como vimos, grande parte dos autores que tratam sobre os trens turísticos partilham desse discurso sobre o que apontam como sucateamento do setor ferroviário. Apesar de frequente em publicações e presente nas falas da ABPF (RIBEIRO, 2007) essa noção associada ao fim da era ferroviária é questionada por autores de outras áreas (NUNES, 2013). Correta ou não, o que podemos afirmar é que esta intepretação esteve presente em todas as monitorias que presenciamos no Museu Funicular e Trem dos Ingleses, ambos em Paranapiacaba. Além disso, são indissociáveis do forte teor nostálgico sempre adotado pela Associação.

\subsection{O Trem Turístico como Estratégia de Uso e Preservação}

Os documentos apresentados pela ABPF ao CONDEPHAAT durante o processo de tombamento da E.F. Perus Pirapora são fontes relevantes para compreender os propósitos do grupo (PROCESSO CONDEPHAAT 21273/80, 1980). O exemplo esclarece as relações entre preservação e

\footnotetext{
${ }^{6}$ Pronunciamento realizado em 20 de dezembro de 1972. Entrega da primeira locomotiva fabricada pela empresa General Eletric (GE) fabricada no Brasil (ANDREAZZA, 1974).
} 
turismo dentro dos propósitos da ABPF. Os argumentos para preservação apresentados destacavam o fato de uma ferrovia em bitola de $60 \mathrm{~cm}$ e composta por um acervo impar de locomotivas a vapor (MORAES, 2016). O trem turístico aparece como uma possibilidade de uso do patrimônio, uma vez que as operações comerciais - transporte de cimento - estavam encerradas.

A relação apresentada é compatível com os resultados encontrados na Revista Ferrovia. Conforme Dollinger (1980b, p. 34) a finalidade de um trem turístico é angariar rendas para manter o acervo histórico. Além disso, o termo "museu dinâmico", indicando contrariedade à preservação estática e comum nas publicações, aparece também ao longo do processo. A possibilidade de integrar as locomotivas a vapor ao acervo de algum museu foi amplamente criticada pela ABPF (PROCESSO CONDEPHAAT 21273/80, 1980).

O mesmo exemplo apresenta a preservação da ferrovia e locomotivas a vapor como objetivo maior. Apesar de compactuar com a relevância do bem, o foco excessivo dado ao material rodante foi também responsável por distanciar a relação da ferrovia com a fábrica a qual prestou serviços, a Companhia Brasileira de Cimento Portland Perus (AUTOR, 2016). Com a inclusão das locomotivas, linhas e outros materiais, a E.F. Perus Pirapora foi tombada em 1987. Por curiosidade, a ABPF nunca chegou a operar um trem turístico nesta ferrovia. ${ }^{7}$

A Viação Férrea Campinas Jaguariúna (VFCJ) é o primeiro trem turístico da ABPF, inaugurado em 1984 (RIBEIRO, 2007; ALLIS, 2006). Contudo, as características dos projetos da Associação já se manifestavam nas ações que antecederam sua criação.

O primeiro evento organizado pela ABPF, com passeio em composição tracionada por locomotiva a vapor entre São Paulo e Jundiaí, foi noticiado com forte teor nostálgico como se nota no titulo da reportagem: "A velha dama, despertando paixões como antigamente" (KARABACIN, 1981). A nostalgia está presente nas descrições: “As crianças puderam conhecer e sentir de perto uma 'maria-fumaça', a imponente Pacific 353 - velha dama para os íntimos". Uma ação similar foi realizada no ano seguinte, tendo como destino Paranapiacaba.

As excursões realizadas e as menções ao projeto de criação do museu dinâmico (DEL BIANCO, 1980; DOLLINGER, 1980a; DOLLINGER, 1980b) demonstram os trens turísticos como ação alinhada aos objetivos de preservação da ABPF. Ainda que as reais origens do interesse de uso turístico das ferrovias possam ser anteriores a ABPF, o pioneirismo da Associação é válido para operação e seu modelo de gestão com trabalho voluntário (COOPER, 2011). Este modelo segue vigente e foi replicado em outros trens turísticos da Associação.

Assim sendo, os interesses na preservação do patrimônio e da memória ferroviária são as principais relações entre as ações pioneiras da ABPF e os atuais serviços ferroviários turísticos. No

\footnotetext{
${ }^{7}$ Atualmente, o Instituto de Ferrovias e Preservação do Patrimônio Cultural (IFPPC) é o responsável pela preservação da ferrovia. A Associação sem fins lucrativos realiza visitas ao acervo e passeios ferroviários (IFPPC, 2017), motivo que nos levou a incluí-la na lista dos trens turísticos apresentadas no artigo.
} 
primeiro momento, uma atuação frente ao risco de perda ocasionado pela situação das ferrovias. No segundo, uma atribuição de uso abrangente para os bens da extinta RFFSA.

\section{CONSIDERAÇÕES FINAIS}

A revisão bibliográfica deixou claro que nem sempre o uso turístico da ferrovia esteve relacionado ao patrimônio. Essa aproximação aparece na legislação - Resolução n 359/2003 da ANTT - e de forma gradativa nas publicações a partir dos anos 2000. O processo de privatização da RFFSA é mencionado com frequência e os autores (PAOLILLO; REJOWSKI, 2002; RONÁ, 2002) partilham de uma interpretação de degradação do setor ferroviário.

Não partilhamos do entendimento de degradação ou fim da ferrovia, entendimento também presente em parte das proteções oficiais (AUTOR, 2016). De toda forma, a escassez dos serviços ferroviários para passageiros influencia o interesse e a experiência dos turistas, ponto onde sim concordamos com o conjunto de autores.

A pesquisa bibliográfica confirma o que também identificamos por fontes documentais (REVISTA FERROVIA, 1982), que na década de 1980 não havia no país outro serviço que tivesse o trem como atrativo principal, estratégia adotada pela ABPF associada à ideia de museu dinâmico.

Na década atual, a maioria numérica de trens operados e a frequente menção em estudos e projetos para novos trens turísticos, nos permitem afirmar que a ABPF é uma referência para o setor. Neste novo cenário, a ABPF aparece principalmente como parceira da administração municipal para a implantação dos projetos. É o caso dos projetos de como os presentes nas cidades de São Roque, Araçatuba e Guararema. Outro indicador desta importância é a presença de representantes do grupo também na diretoria da ABOTTC.

Por outro lado, sem questionar as capacidades técnicas e importância da ABPF nestes projetos de uso e preservação, o artigo demonstra também que a opção pelo vapor é também fruto da noção e dos valores construídos pelo grupo na década de 1980. Por isso, cremos que a incorporação destes valores - que representam memórias de um grupo específico - pelo Poder Público através de projetos ou orientações é preocupante. Assim, considerando que o vapor não é a única opção, esperamos uma problematização maior na escolha das características destes serviços, evitando a criação de cenários turísticos ou gastos desequilibrados.

\section{REFERÊNCIAS BIBLIOGRÁFICAS}

ALLIS, T.; BRAMBATTI, L. E.. Trens e turismo. Caxias do Sul: Meridiano, 2010.

ALLIS, T. Turismo, patrimônio cultural e transporte ferroviário: um estudo sobre as ferrovias turísticas no Brasil e na Argentina. 2006. 232f. Dissertação (Mestrado) - Programa de Pós-Graduação em Integração da América Latina, Universidade de São Paulo, 2006. 
ANDREAZZA, M. D. Perspectivas para os transportes. Rio de Janeiro: S.-G. M.T. 1974

ASSOCIAÇÃO BRASILEIRA DAS OPERADORAS DE TRENS TURÍSTICOS E CULTURAIS (ABOTTC) (Brasil). Trem Cultural dos Ingleses. Disponível em: <http://www.abottc.com.br/cultural-train-of-thebritish/?lang=es>. Acesso em: 01 set. 2017.

ASSOCIAÇÃO DOS ENGENHEIROS DA ESTRADA DE FERRO SANTOS A JUNDIAÍ (São Paulo). Revista Ferrovia: Sobre a Revista. Disponível em: <http://www.aeefsj.org.br/site/?page_id=6723>. Acesso em: 06 dez. 2015.

BRASIL. AGENCIA NACIONAL DE TRANSPORTES TERRESTRES (ANTT). Trens Turísticos e Comemorativos. Resolução no 359, de 26/11/2003, por meio da qual estabeleceu procedimentos relativos à operação dos trens turísticos, histórico-culturais, e comemorativos. Disponível em: <http://www.antt.gov.br/>. Acesso em: 30 jan. 2014a.

BRASIL. AGENCIA NACIONAL DE TRANSPORTES TERRESTRES (ANTT).. . Trens turísticos e comemorativos. 2015. Trens Turísticos e Culturais autorizados no período de 2004 a 2015. Disponível em: <http://www.antt.gov.br/passageiros/Trens_turisticos_e_comemorativos.html>. Acesso em: 01 set. 2017.

BRASIL. INSTITUTO DO PATRIMÔNIO HISTÓRICO E ARTÍSTICO NACIONAL (IPHAN). Patrimônio Ferroviário. Disponível em:<portal.iphan.gov.br/>. Acesso em: 30 jan. 2014.

BRASIL. INSTITUTO DO PATRIMÔNIO HISTÓRICO E ARTÍSTICO NACIONAL (IPHAN). Cartas patrimoniais. Rio de Janeiro: IPHAN, 1995

BRASIL. MINISTÉRIO DO TURISMO. (Org.). Cartilha de Orientação para Proposição Projetos de Trens Turísticos e Culturais. $2010 . \quad$ Disponível em: <http://www.turismo.gov.br/export/sites/default/turismo/o_ministerio/publicacoes/downloads_pu blicacoes/cartilha-final-b.pdf>. Acesso em: 30 jan. 2014.

BRASIL. INSTITUTO BRASILEIRO DE GEOGRAFIA E ESTATÍSTICA. (Org.). Anuário Estatístico do Brasil. Rio de Janeiro: IBGE, 1969.

BRASIL. INSTITUTO BRASILEIRO DE GEOGRAFIA E ESTATÍsTICA. (Org.). Anuário Estatístico do Brasil. Rio de Janeiro: IBGE, 1972.

BRASIL. INSTITUTO BRASILEIRO DE GEOGRAFIA E ESTATÍSTICA. (Org.). Anuário Estatístico do Brasil. Rio de Janeiro: IBGE, 1975.

BRASIL. INSTITUTO BRASILEIRO DE GEOGRAFIA E ESTATÍSTICA. (Org.). Anuário Estatístico do Brasil. Rio de Janeiro: IBGE, 1978.

BRASIL. INSTITUTO BRASILEIRO DE GEOGRAFIA E ESTATÍSTICA. (Org.). Anuário Estatístico do Brasil. Rio de Janeiro: IBGE, 1981.

BRASIL. INSTITUTO BRASILEIRO DE GEOGRAFIA E ESTATÍSTICA. (Org.). Anuário Estatístico do Brasil. Rio de Janeiro: IBGE, 1984.

BRASIL. INSTITUTO BRASILEIRO DE GEOGRAFIA E ESTATÍSTICA. (Org.). Anuário Estatístico do Brasil. Rio de Janeiro: IBGE, 1987

COOPER, M. Brazilian Railway Culture. Cambridge Scholars, 2011. 
CENÁRIO, Brasilia, V.5, n.9 | 39 - 40 | Dez. 2017 | p. 39 hon http://www.cultura.sp.gov.br/SEC/Condephaat/Bens\%20Tombados/lista set.13 BensTombOrdMuni c\%C3\%ADpios Site.pdf. Acesso em: 30 jan. 2014.

DEL BIANCO, A. H. Aos amigos ferroviários. Revista Ferrovia, São Paulo, v.69, n. 1, p. 22, novembro 1979. Bimestral.

DOLLINGER, P. Associação Brasileira de Preservação Ferroviária. Revista Ferrovia, São Paulo, n. 71, p.34-34, mar. 1980. Bimestral. Órgão da Associação dos Engenheiros da Estrada de Ferro Santos à Jundiaí.

ESTRADA DE FERRO CAMPOS DO JORDÃO (São Paulo). Secretaria dos Transportes Metropolitanos. Apresentação.Disponível em: <http://www.efcj.sp.gov.br/>. Acesso em: 01 set. 2017.

FRAGA, C. C. I. ; FERNANDES, E. M. R.; CASTRO, R. T. Transporte. 2. ed. Rio de Janeiro: Cecierj, 2012.

INSTITUTO DE FERROVIAS E PRESERVAÇÃO DO PATRIMÔNIO CULTURAL (Brasil). Projeto a volta do trem das onze: visita ao eco-museu com passeio de maria-fumaça e muito mais. Disponível em: <http://efperuspirapora.blogspot.com.br/>. Acesso em: 01 set. 2017.

KARABACHIN, A. Agenda: Precioso Acervo da Estradinha, Ameaçado (Jornal da Tarde SP 16/09/1981). Revista Ferrovia, São Paulo, v. 1, n. 80, p.53, set. 1981a. Bimestral.

KARABACHIN, A.. Agenda: A velha dama, despertando paixões como antigamente (Jornal da Tarde 28/09/1981). Revista Ferrovia, São Paulo, v. 1, n. 80, p.53, set. 1981b. Bimestral.

KARABACHIN, A. Agenda: no velho trem de ferro 700 passageiros e muita saudade (Jornal da Tarde SP - 19/07/1982). Revista Ferrovia, São Paulo, v. 1, n. 85, p.35 set. 1982. Bimestral.

LOHMANN, Guilherme; FRAGA, Carla; CASTRO, Rafael. Transportes e destinos turísticos: planejamento e gestão. Rio de Janeiro: Elsevier, 2013.

MATOS, L. F. Estação Memória: um estudo das entidades de preservação ferroviária do Estado do Rio de Janeiro. CEDOC. Fundação Getulio Vargas, 2010.

MORAES, E. H. Os bens ferroviários nos tombamentos do Estado de São Paulo (1969 - 1984). 2016. 191 f. Dissertação (Mestrado) - Curso de Mestrado em Arquitetura e Urbanismo, Faculdade de Arquitetura, Artes e Comunicação (FAAC), Universidade Estadual Paulista (UNESP), Bauru, 2016. Disponível em: . Acesso em: 01 ago. 2017.

MORAES, J.E.C.D. Porque Preservar o Patrimônio Histórico Ferroviário. In: Revista Ferrovia. São Paulo: Associação dos Engenheiros da E. F. Santos a Jundiaí, v. 72, maio 1980. Bimestral.

MRS LOGÍSTICA. Guararema agora tem trem de passageiros. 2015. Disponível em: $<$ https://www.mrs.com.br/post-newsletter/trem-de-passageiro-faz-viagem-inaugural-emguararema/>. Acesso em: 01 set. 2017.

OLIVEIRA, E. R. Patrimônio Ferroviário do Estado de São Paulo: As condições de preservação e uso dos bens culturais. Projeto História (PUCSP), v. 40, p. 179-203, 2010.

PALHARES, G. L.. Transportes Turísticos. 2 ed. São Paulo: Aleph, 2006. 
PAOLILLO, A. M. ; REJOWSKI, M. Transportes. 3. ed. São Paulo: Aleph, 2006.

PREFEITURA DE BAURU (Bauru). Projeto Ferrovia para Todos. Página fora do ar.. Disponível em: <http://www.bauru.sp.gov.br/secretarias/sec_cultura/patrimonio.aspx>. Acesso em: 04 abr. 2015.

REVISTA FERROVIA. São Paulo: Associação dos Engenheiros da E. F. Santos a Jundiaí, v. 84, maio 1982. Bimestral.

RIBEIRO, S. B. Na Linha da Preservação: o leito ferroviário Campinas - Jaguariúna. Campinas: Tratore Livros, 2007.

RONÁ, R. D. Transportes no Turismo. Barueri: Manole, 2002.

SÃO PAULO (Estado). CONSELHO DE DEFESA DO PATRIMÔNIO HISTÓRICO, ARQUEOLÓGICO, ARTíSTICO E TURISTÍSTICO (CONDEPHAAT). Processo de tombamento 21273/80. Acervo da Estrada de Ferro Perus-Pirapora-Cajamar. CONDEPHAAT, 1980

SERVIÇO BRASILEIRO DE APOIO ÀS MICRO E PEQUENAS EMPRESAS (Brasil). Trens Turísticos e Culturais do Brasil. Brasilia: Sebrae, 2016. Disponível em: <http://www.bibliotecas.sebrae.com.br/chronus/ARQUIVOS_CHRONUS/bds/bds.nsf/1e1cfdcbdf6b1 a45ce04e7999efad58a/\$File/7250.pdf>. Acesso em: 01 set. 2017.

\section{Agradecimentos}

Agradecemos o apoio financeiro recebido da Fundação de Amparo à Pesquisa do Estado de São Paulo (FAPESP), por meio de bolsa de mestrado (Processo FAPESP 2014/04139-6). 